\title{
Qualitative Posttreatment Diffusion- Weighted Imaging as a Predictor of 90-day Outcome in Stroke Intervention
}

\author{
Adam A Dmytriw (10, Abdullah Alrashed, Alejandro Enriquez-Marulanda, \\ Shadi Daghighi, Ghouth Waggas, Aria Rezaie, Chinthaka Heyn, Amy Yu®, \\ Richard I Aviv, Leodante Da Costa, Victor XD Yang
}

\begin{abstract}
Purpose: The aim was to assess the ability of post-treatment diffusion-weighted imaging (DWI) to predict 90-day functional outcome in patients with endovascular therapy (EVT) for large vessel occlusion in acute ischemic stroke (AIS). Methods: We examined a retrospective cohort from March 2016 to January 2018, of consecutive patients with AIS who received EVT. Planimetric DWI was obtained and infarct volume calculated. Four blinded readers were asked to predict modified Rankin Score (mRS) at 90 days postthrombectomy. Results: Fifty-one patients received endovascular treatment (mean age 65.1 years, median National Institutes of Health Stroke Scale (NIHSS) 18). Mean infarct volume was $43.7 \mathrm{~mL}$. The baseline NIHSS, 24-hour NIHSS, and the DWI volume were lower for the mRS 0-2 group. Also, the thrombolysis in cerebral infarction (TICI) 2b/3 rate was higher in the mRS 0-2 group. No differences were found in terms of the occlusion level, reperfusion technique, or recombinant tissue plasminogen activator use. There was a significant association noted between average infarct volume and $\mathrm{mRS}$ at 90 days. On multivariable analysis, higher infarct volume was significantly associated with 90-day mRS 3-5 when adjusted to TICI scores and occlusion location (OR 1.01; CI 95\% 1.001-1.03; $p=0.008$ ). Area under curve analysis showed poor performance of DWI volume reader ability to qualitatively predict 90-day mRS. Conclusion: The subjective impression of DWI as a predictor of clinical outcome is poorly correlated when controlling for premorbid status and other confounders. Qualitative DWI by experienced readers both overestimated the severity of stroke for patients who achieved good recovery and underestimated the mRS for poor outcome patients. Infarct core quantitation was reliable.
\end{abstract}

RÉSUMÉ : Prédire de façon qualitative l'évolution de l'état de santé de patients au moyen d'IRM de diffusion à la suite d'AVC traités par thrombectomie endovasculaire. But de l'étude : Au bout de 90 jours, évaluer la capacité des IRM de diffusion (diffusion-weighted imaging) à prédire l'évolution fonctionnelle de patients ayant suivi un traitement endovasculaire à la suite d'un AVC aigu ayant affecté un vaisseau sanguin important. Méthodes : Pour ce faire, nous avons examiné une cohorte rétrospective de patients vus consécutivement de mars 2016 à janvier 2018 et ayant bénéficié d'un traitement endovasculaire. Des résultats planimétriques d'IRM de diffusion ont ainsi été obtenus, ce qui nous a permis de calculer le volume des AVC. On a ensuite demandé à quatre analystes à l'aveugle (blinded readers) de prédire des scores à l'échelle modifiée de Rankin (EMR) au bout de 90 jours de traitement. Résultats : Au total, 51 patients ont bénéficié d'un tel traitement (âge moyen 65,1 ; score médian de 18 à la NIH Stroke Scale ou NIHSS). Le volume moyen des AVC était de $43,7 \mathrm{~mL}$. Dans le cas des analystes à l'aveugle 0 - 2, tant les scores de départ à la NIHSS, les scores à la NIHSS une fois 24 heures passées que les volumes détectés par IRM de diffusion étaient inférieurs alors que les taux de TICI $2 b / 3$ prédits étaient plus élevés. Aucune différence n'a été observée en matière de niveau d'occlusion, de techniques de reperfusion ou d'utilisation du t-PA faisant appel à la technologie recombinante. Une association notable a été par ailleurs constatée entre le volume moyen des AVC et les scores à l'EMR au bout de 90 jours. Dans le cadre d'une analyse multivariée, il est aussi à noter que des volumes élevés d'AVC ont été associés de façon notable à des scores de 3 à 5 à l'EMR une fois ces derniers ajustés en fonction des taux de recanalisation TICI $2 \mathrm{~b} / 3$ et de l'emplacement de l'occlusion (rapport des cotes 1,01 ; IC $95 \%$ $1,001-1,03 ; p=0,008$ ). En terminant, la méthode d'analyse dite de «la surface sous la courbe » (AUC analysis) a montré une faible capacité de prédiction qualitative des scores à l'EMR en tenant compte des volumes d'AVC tels que révélés par les IRM de diffusion. Conclusion : Les impressions subjectives d'analystes à l'aveugle se basant sur des IRM de diffusion afin de prédire l'évolution clinique de patients sont faiblement corrélées une fois contrôlés leur état pré-morbide et d'autres facteurs de confusion. En somme, une telle lecture qualitative a à la fois surestimé la gravité des AVC de patients qui se sont par la suite bien rétablis et sous-estimé les scores à l'EMR de ceux dont l'évolution de l'état de santé s'est avérée défavorable. Cela étant, la quantification principale de ces AVC s'est révélée fiable.

Keywords: Diffusion-weighted imaging, Stroke intervention, Modified Rankin Score, Ischemic stroke

doi: $10.1017 / \operatorname{cjn} .2019 .330$

Can J Neurol Sci. 2020; 47: 160-166

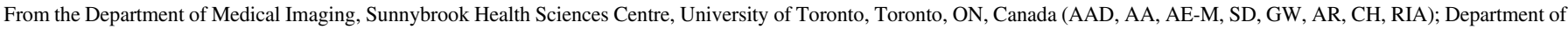

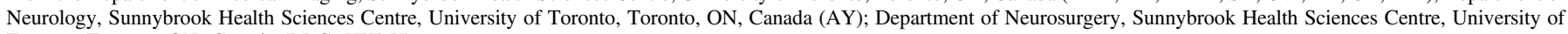
Toronto, Toronto, ON, Canada (LDC, VXDY)

Received October 18, 2019. Final Revisions Submitted November 9, 2019. Date of Acceptance November 23, 2019.

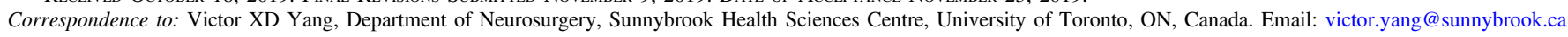




\section{INTRODUCTION}

Acute ischemic stroke (AIS) represents the leading cause of disability in adults and is the second leading cause of death worldwide. $^{1-8}$ Since the publication of the major 2015 stroke trials, the gold standard treatment for large vessel occlusion (LVO) anterior circulation strokes is endovascular mechanical thrombectomy (MT). The goal of this intervention is to rapidly recanalize the occluded vessel and facilitate early reperfusion of the salvageable brain tissue contained within ischemic penumbra shown to improve the clinical and functional patient outcome. $^{9-12}$

Posttreatment imaging combined with relevant clinical information is commonly utilized for prognostication and ultimately to predict clinical outcomes. These measures include National Institutes of Health Stroke Scale (NIHSS) 24-hour after treatment, modified Rankin Score (mRS) at discharge and post-revascularization infarct volume. ${ }^{13-16}$ Regarding noncontrast CT, it has been suggested the Alberta stroke program early computed tomography score (ASPECTS) may be superior to clinical measures such as DRAGON in predicting outcome. ${ }^{17,18}$ However, previous investigations showed that the degree of diffusion restriction on magnetic resonance imaging (MRI) at 5 days did not reliably predict the clinical outcome in the pre-endovascular era. ${ }^{19}$

We hypothesized that post-revascularization diffusion-weighted imaging (DWI) may poorly estimate the severity of stroke in patients who undergo MT for emergent LVO. In this study, we specifically assessed whether post-revascularization DWI can qualitatively on interpretation or quantitatively with volume calculation, predict the discharge and 90-day clinical outcomes after endovascular therapy (EVT) reliably, as defined by the mRS.

The objective of this study was to determine if experienced readers could predict $\mathrm{mRS}$ at 90 days when blinded to these outcomes and given only the post-therapeutic DWI images.

\section{MethodS}

We retrospectively analyzed all consecutive patients who underwent endovascular thrombectomy at our tertiary stroke center from March 2016 to January 2018. Research ethics board approval was obtained. We identified 80 patients with AIS who underwent endovascular reperfusion treatment. Inclusion criteria were: (1) acute stroke with LVO and (2) DWI obtained typically within 48 hours of reperfusion treatment. Twenty-nine were excluded due to lack of DWI following the reperfusion treatment.

\section{Clinical Analysis}

Stroke severity using NIHSSS at baseline and 24 hours was assessed by a stroke neurologist. Patients' functional outcome was assessed using the mRS at baseline, discharge, and 90 days. The primary outcome was poor neurologic outcome using the mRS score 90 days after stroke onset defined as mRS $>2$ and determined by a stroke neurologist.

\section{Imaging Analysis}

MRI sequences minimally included axial fluid-attenuated inversion recovery (FLAIR) TR (repetition time)/TE (echo
time)/TI (inversion time) 8000/120/200, field of view (FOV) $22 \mathrm{~cm}$, matrix $320 \times 224$, section thickness (ST) 5, $1 \mathrm{~mm}$ gap, gradient T2 (1100/35/20 TR/TE/FA (flip angle), FOV $24 \mathrm{~cm}$, matrix $320 \times 224$, ST 5, $1 \mathrm{~mm}$ gap), DWI $(8125 / \mathrm{min}(\mathrm{TR} / \mathrm{TE})$, FOV $26 \mathrm{~cm}$, matrix $128 \times 128$, ST of $5 \mathrm{~mm}$ with no gap and sagittal T1 FLAIR TR/TE/TI 2163/26/750, FOV $22 \mathrm{~cm}$, matrix $320 \times 224$, ST 5, $1 \mathrm{~mm}$ gap.

For quantitative data, the final infarct volume was measured on the DWI or FLAIR on follow-up MRI study using Medical Image Processing, Analysis and Visualization (Center for Information Technology, National Institutes of Health, Version: 7.2.0) by an experienced neuroradiologist.

Three radiologists and one neurologist used the DWI to qualitatively predict clinical outcome at 90 days posttreatment based on infarct location and appearance. Readers were not restricted in the criteria they could use for estimation, although they were given the same DWI images only. A 90-day mRS scoring was predicted by a stroke neurologist, with all readers blinded to clinical, other imaging, and outcome data.

\section{Treatment and Angiographic Recanalization Assessment}

Three neurointerventionalists at our institution performed endovascular thrombectomy for all patients included in this study. Most patients (78.4\%) underwent stent retriever thrombectomy as the primary treatment, with either the Trevo system (Stryker; Kalamazoo, Michigan, USA) or Solitaire AB device (ev3; Irvine, California, USA). The remaining minority of patients were treated with aspiration with the Penumbra separator (Penumbra Inc., Alameda, California, USA).

\section{Statistical Analysis}

Clinical and imaging baseline characteristics of the patients were analyzed. This study was reviewed and approved by our institutional research ethics board.

Categorical variables are reported as proportions. Continuous variables are reported as mean \pm standard deviation (SD) or median [interquartile range (IQR)] as appropriate according to the distribution of the data. Comparison between patients who suffered a stroke and had a good neurological outcome vs. poor neurological outcome at 90 days measured with the mRS was undertaken. Categorical variables were compared using the Fisher's exact test. Continuous variables were compared using either two-sample $t$-test or the Mann-Whitney U-test according to the normality assumption. Correlation analysis was performed using Spearman's correlation, with 95\% CIs. A multivariate logistic regression model for poor outcomes on last follow-up (mRS $>2$ ) was performed. For the evaluation of the prediction of $\mathrm{mRS}$ based on the readers, the command rocreg was used. A $p$-value of $<0.05$ was considered significant. All analyses were performed using STATA 14 software (StataCorp, Texas, USA).

\section{ReSUlts}

Fifty-one patients received endovascular treatment during the study period with posttreatment MRI/DWI (Table 1). The mean age was $65.1 \pm 14.5$ years and men comprised $56.9 \%(29 / 51)$. The median NIHSS score at admission was 18 (IQR 13-20) at 
Table 1: Baseline clinical and imaging characteristics, treatment, and predictors of 3-month $\mathrm{mRS}$

\begin{tabular}{|c|c|c|c|c|}
\hline Variables & All patients $(n=51)$ & mRS 0-2 & mRS 3-5 & $p$-Value \\
\hline Age (year) & $65.1 \pm 14.5$ & $62.4 \pm 14.5$ & $69.2 \pm 13.8$ & 0.105 \\
\hline \multicolumn{5}{|l|}{ Sex } \\
\hline Male & $29(56.9 \%)$ & $17(54.8 \%)$ & $12(60.0 \%)$ & \multirow[t]{2}{*}{0.778} \\
\hline Female & $22(43.1 \%)$ & $14(45.2 \%)$ & $8(40.0 \%)$ & \\
\hline ASPECTS (a) & $7.5 \pm 1.5$ & $7.4 \pm 1.6$ & $7.5 \pm 1.4$ & 0.828 \\
\hline Baseline NIHSS score (b) & 18 (IQR 13-20) & 17 (IQR 12-19) & 18.3 (IQR 17-21) & 0.046 \\
\hline 24 hours NIHSS score (b) & 8 (IQR 1-15) & 2 (IQR 1-5) & 15.5 (IQR 13-20) & $<0.001$ \\
\hline DWI Volume (mL) & 21.8 (IQR 6.5-58.9) & 8.8 (IQR 4.2-35) & 45.8 (IQR 17.7-95.8) & 0.003 \\
\hline \multicolumn{5}{|l|}{ Occlusion level } \\
\hline Vertebrobasilar & $4(7.8 \%)$ & $3(9.7 \%)$ & $1(5.0 \%)$ & \multirow[t]{4}{*}{0.702} \\
\hline ICA & $14(27.5 \%)$ & $7(22.6 \%)$ & $7(35.0 \%)$ & \\
\hline MCA M1 & $29(56.9 \%)$ & $19(61.3 \%)$ & $10(50.0 \%)$ & \\
\hline MCA M1/M2 & $4(7.8 \%)$ & $2(6.5 \%)$ & $2(10.0 \%)$ & \\
\hline \multicolumn{5}{|l|}{ Reperfusion technique } \\
\hline Stent retriever & $40(78.4 \%)$ & $23(74.2 \%)$ & $17(85.0 \%)$ & \multirow[t]{4}{*}{0.919} \\
\hline Aspiration device & $1(2.0 \%)$ & $1(3.2 \%)$ & $0(0.0 \%)$ & \\
\hline ADAPT technique & $5(9.8 \%)$ & $4(12.9 \%)$ & $1(5.0 \%)$ & \\
\hline Other & $5(9.8 \%)$ & $3(9.7 \%)$ & $2(10.0 \%)$ & \\
\hline \multicolumn{5}{|l|}{$\mathrm{tPA}$} \\
\hline $\mathrm{tPA}$ & $36(70.6 \%)$ & $23(74.2 \%)$ & $13(65.0 \%)$ & \multirow[t]{2}{*}{0.539} \\
\hline No tPA & $15(29.4 \%)$ & $8(25.8 \%)$ & $7(35.0 \%)$ & \\
\hline TICI $2 b / 3$ & $40(78.4 \%)$ & $29(93.6 \%)$ & $11(55.0 \%)$ & 0.002 \\
\hline
\end{tabular}

$n(\%), p$-Value: Fisher's exact test.

Median (Interquartile range), $p$-Value: Mann-Whitney U-test.

Mean ( \pm standard deviation), $p$-Value: Two-sample $t$-test.

Bold values: $p$-Value $<0.05$.

Missing data: (a) 4 (b) 2 .

ICA, internal carotid artery; MCA, middle carotid artery.

admission. Mean infarct volume was $43.7 \mathrm{~mL}$. Median time of post-MT MRI was 2 days (IQR 2-5).

Among the patients examined, $31(60.8 \%)$ had a favorable outcome (mRS $\leq 2$ at 90 days) and $20(39.2 \%)$ a poor outcome $(\mathrm{mRS} \geq 3)$. Mortality on last follow-up was $3(5.9 \%)$. Thrombolysis in cerebral infarction (TICI) with $2 \mathrm{~b} / 3$ ( $>50 \%$ of occluded territory/complete reperfusion) was achieved in (40/51) 78.4\% of cases.

The demographics and treatment characteristics of those with mRS 0-2 were compared to cases with mRS 3-5 (Table 1). We found no differences in terms of mean age, sex, or ASPECTS scores. The baseline NIHSS scores, 24-hour NIHSS score, and DWI volume were lower for the mRS 0-2 group. No differences were found in terms of the occlusion level, occlusion territory (vertebrobasilar territory, basal ganglia/insula territory, cingulate/hippocampus territory, and lobar territory), reperfusion technique, or use of tPA. There was, however, a higher rate of TICI $2 b / 3$ after treatment in the mRS 0-2 group.

A multivariate analysis showed that a higher DWI volume was associated with poor neurological outcome $(\mathrm{mRS}>2)$ at
90 days (OR 1.01; CI 95\% 1.001-1.03; $p=0.04$ ), even when adjusting for vessel occlusion location and TICI $2 b / 3$ rates (Table 2).

Diagnostic accuracy of the readers to predict $m R S>2$ scores at discharge and 90 days, based on DWI volume, was poor as none had an area under curve (AUC) $>0.5$ on receiver operator characteristic curves. There was also no significant difference between the readers in regard to the prediction of poor neurological outcome measured by $\mathrm{mRS}$ for both admission and 90-day follow-up rates ( $p=0.61$ and $p=0.45$, respectively) (Table 3). Ability to predict mRS was not improved if the MRI occurred at any point on the IQR (1-5 days) (Table 4$)$.

\section{Discussion}

DWI can play an important role in the setting of emergent LVO and indeed acute stroke as a whole as regards patient selection for revascularization; however, it historically has not provided a relevant prediction for the 90 days clinical outcome in the pre-endovascular era. ${ }^{20,21}$ 


\section{Table 2. Infarction location characteristics}

\begin{tabular}{l|c}
\hline Side & \\
\hline Left & $22(43.1 \%)$ \\
\hline Right & $24(47.1 \%)$ \\
\hline Bilateral & $5(9.8 \%)$ \\
\hline Vertebrobasilar territory & $4(7.8 \%)$ \\
\hline Basal ganglia/Insula & $38(74.5 \%)$ \\
\hline Cingulate/Hippocampus & $2(3.9 \%)$ \\
\hline Lobar & $28(54.9 \%)$ \\
\hline
\end{tabular}

Table 3. Predictors of poor outcome $(\mathrm{mRS}>2)$ at 90-day follow-up

\begin{tabular}{l|c|c}
\hline Variable & OR (CI 95\%) & $\boldsymbol{p}$-Value \\
\hline Location & \multicolumn{3}{|l}{} \\
\hline ICA & $2.6(0.14-48.2)$ & 0.63 \\
\hline MCA M1 & $1.1(0.06-18.3)$ & 0.96 \\
\hline MCA M1/M2 & $1.8(0.05-65.3)$ & 0.75 \\
\hline TICI 2b/3 & $0.08(0.01-0.52)$ & $\mathbf{0 . 0 0 8}$ \\
\hline DWI Volume $(\mathrm{mL})$ & $1.01(1.001-1.03)$ & $\mathbf{0 . 0 4}$ \\
\hline
\end{tabular}

Bold values: $p$-Value $<0.05$ (binary multivariable logistic regression) ICA, internal carotid artery; MCA, middle carotid artery.

Table 4. Diagnostic accuracy prediction of $\mathrm{mRS}$ per reader based on DWI

\begin{tabular}{|c|c|c|c|}
\hline \multicolumn{4}{|c|}{ Prediction of poor outcome mRS at discharge per reader } \\
\hline Reader & $\mathbf{A U C}$ & $95 \% \mathrm{CI}$ & $p$-Value \\
\hline 1 & 0.38 & $0.21-0.54$ & \multirow[t]{4}{*}{0.61} \\
\hline 2 & 0.39 & $0.24-0.55$ & \\
\hline 3 & 0.41 & $0.25-0.57$ & \\
\hline 4 & 0.34 & $0.19-0.48$ & \\
\hline \multicolumn{4}{|c|}{ Prediction of poor outcome $\mathrm{mRS}$ at 90 days per reader } \\
\hline Reader & $\mathbf{A U C}$ & $95 \% \mathrm{CI}$ & $p$-Value \\
\hline 1 & 0.37 & $0.20-0.54$ & \multirow[t]{4}{*}{0.45} \\
\hline 2 & 0.42 & $0.25-0.59$ & \\
\hline 3 & 0.39 & $0.23-0.57$ & \\
\hline 4 & 0.32 & $0.17-0.48$ & \\
\hline
\end{tabular}

In the current study, we found that the physician's impression of the DWI as a measure of clinical outcome for a given MT patient is poorly correlated (Figures 1-2) with actual clinical outcome, even with relevant training in the clinical neurosciences. In fact, the DWI appearance both frequently overestimated the



Figure 1. Performance plots for $(A-B)$ readers, $(C)$ mean DWI, and (D) infarct volume versus $m R S$ across the MT for emergent large vessel occlusion cohort at our institution.

severity of stroke for patients who achieved good recovery and underestimated the severity of stroke for poor outcome patients. Moreover, analysis failed to demonstrate any correlation between reader prediction of mRS based on DWI and the 90-day outcome (Figures 3-4).

There are a number of reasons why prediction efforts may have failed. The problem with imaging prognostication is that both brain eloquence and crucial clinical variables are not necessarily considered in sufficient detail and may ultimately be of greater importance. For instance, a right middle carotid artery (MCA) cortical stroke that spares the deep motor fibers and the motor strip can be quite clinically benign but still $>70 \mathrm{cc}$ in volume. The same infarct in a patient with severe congestive heart failure and chronic obstructive pulmonary disease (COPD) may be deadly. Similarly, a small infarct in the right MCA territory involving the lenticulostriates but sparing the cortex after thrombectomy may result in complete and permanent hemiplegia with a small infarct volume. A small infarct volume post-thrombectomy in a mechanically ventilated patient due to the initial severity of symptoms with advanced COPD will undoubtedly not do well. Clinical prognostication is a multifaceted consideration of premorbid status, comorbidities, in addition to infarct volume. Controlling for clinical status as in this study, we must also entertain that it is possible that those with small infarcts in eloquent areas such as the internal capsule still did well because of neuroplasticity. Lastly, it may be that DWI is overly sensitive to ischemia and not predictive even or territorially appropriate deficits in the EVT era.

It is important that the infarct volume, which is more objective than the DWI appearance, correlated well with both discharge and 90-day mRS. Attempts to establish infarct core base on early DWI in acute stroke have been unreliable; however, large-scale studies such as Endovascular Treatment for Small Core and Anterior Circulation Proximal Occlusion with Emphasis on Minimizing CT to Recanalization Times (ESCAPE) have showed an inverse relationship between infarct 


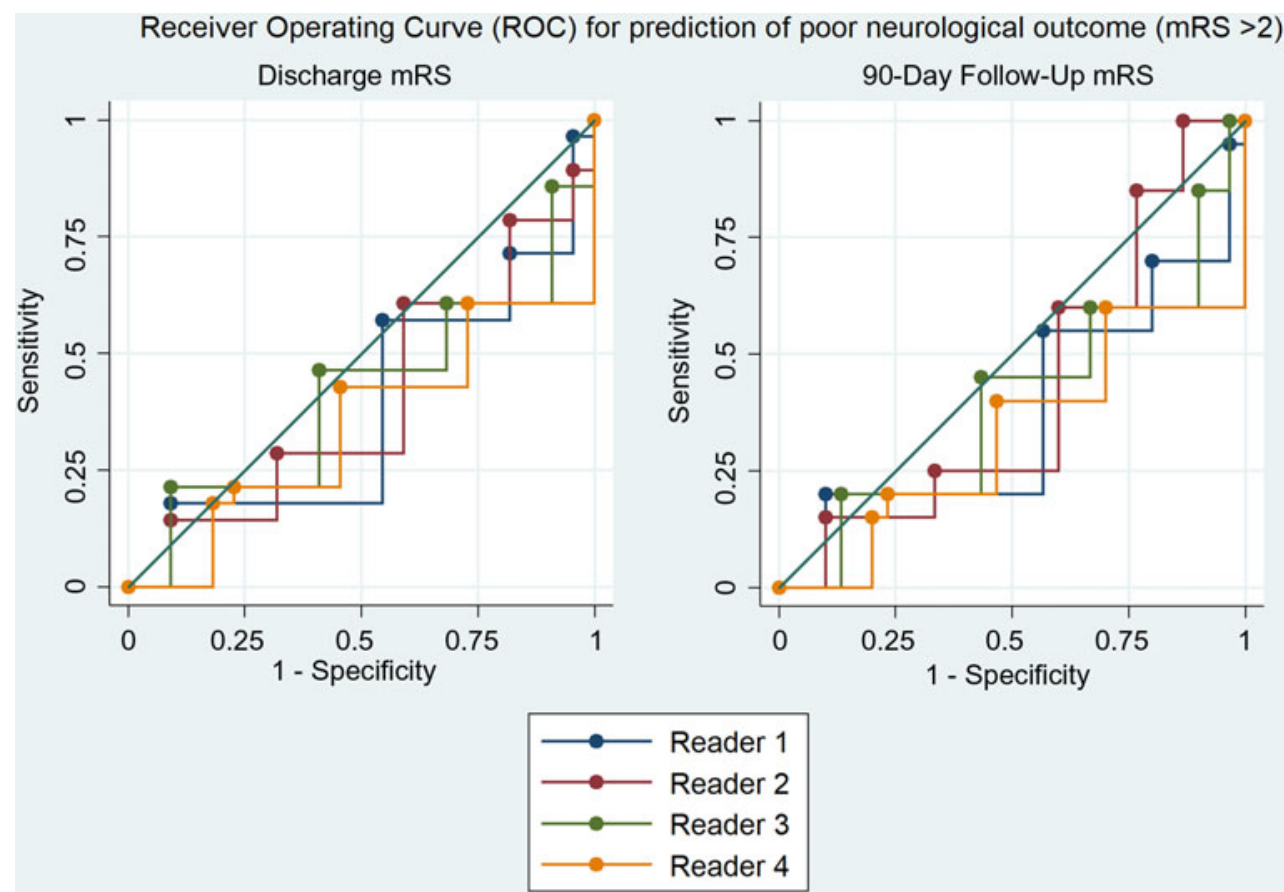

Figure 2. Receiver operating characteristic curve showing neither no correlation between rater prediction of $m R S$ and true 90-day outcome.

(A)

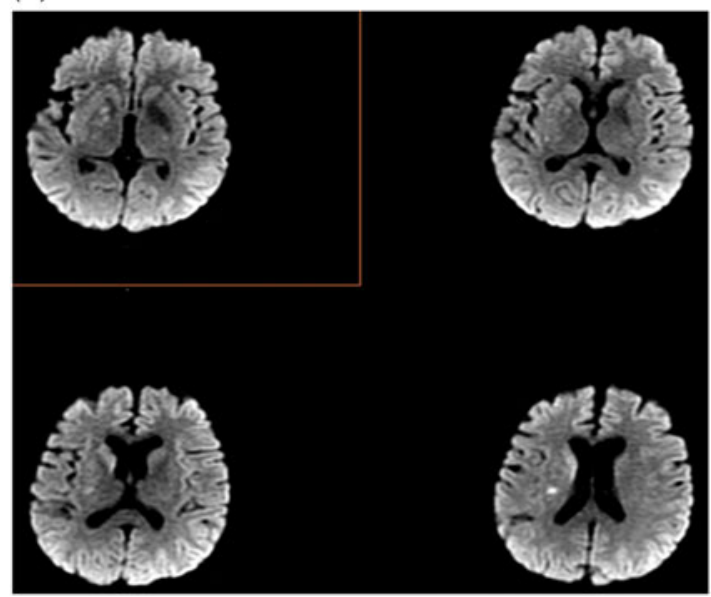

(B)

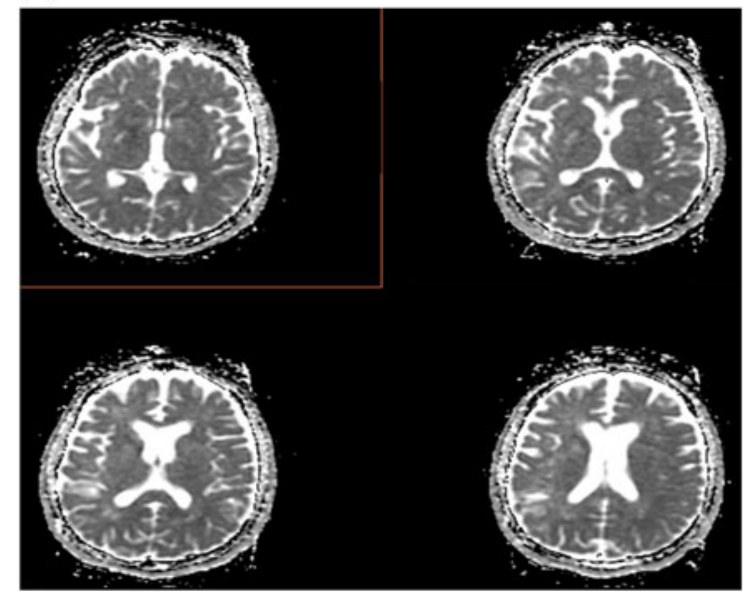

Figure 3. Post-MT case (A) DWI and (B) apparent diffusion coefficient (ADC) maps in which the mRS was rated to be high ( $m R S 4-5)$ by readers on the basis of DWI findings and was ultimately mRS 1 at 90 days.

volume and outcome in general. ${ }^{22}$ Randomized Trial of Revascularization with Solitaire FR Device Versus Best Medical Therapy in the Treatment of Acute Stroke Due to Anterior Circulation Large Vessel Occlusion Presenting Within 8 Hours of Symptom Onset (REVASCAT) subsequently replicated this finding, albeit with the caveat that NIHSS at 24 hours served as a superior predictor of 90 -day $\mathrm{mRS}$ in their cohort. This is also precedented in the pre-endovascular era, in which NIHSS and mRS showed excellent correlation. ${ }^{13,23}$ Moreover, it has been shown that the effect of early recanalization is primarily dependent upon NIHSS in that the effect increases with severity by this clinical measure. ${ }^{24,25}$ Our findings indeed suggest that infarct volume correlates with income. Even though DWI overestimates infarct size in the era of EVT and penumbra salvage, it likely does so in a somewhat-linear fashion making the quantitative finding less surprising. We believe that when an expert interpreting physician regards an MRI, they take into consideration their anticipation of eloquent cortex loss. It is possible that in the era of EVT, a neuroplasticity renders this less reliable than volume.

The ESCAPE trial investigators observed that patients with penumbral pattern fared much better than those who did not 
(A)

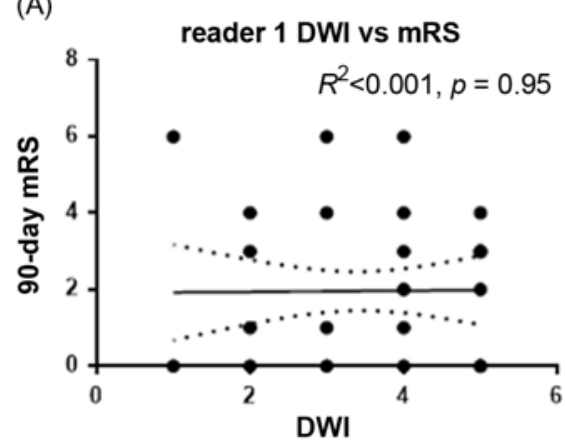

(C)

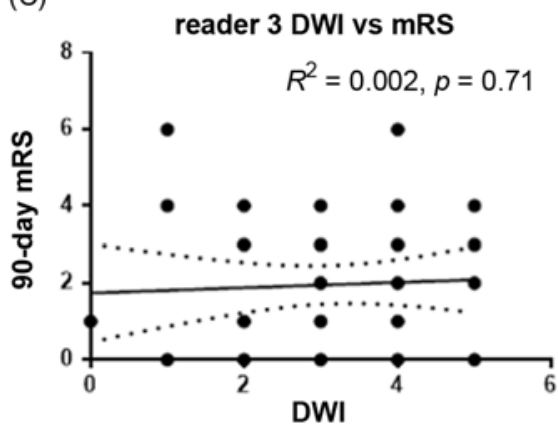

(E)

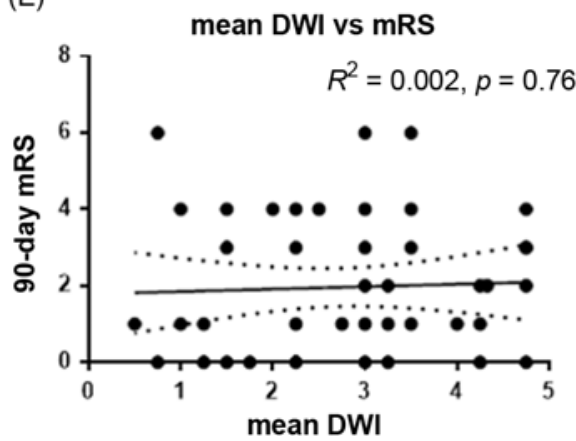

(B)

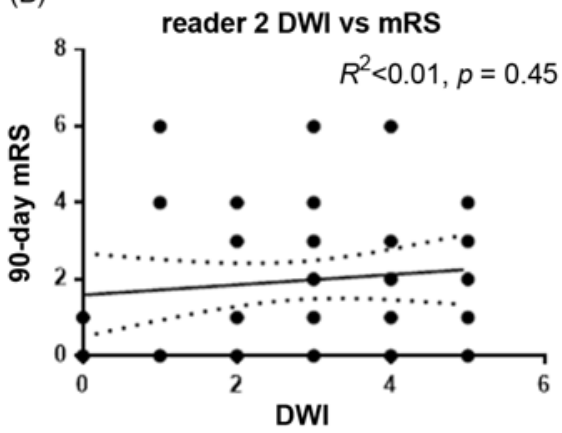

(D)

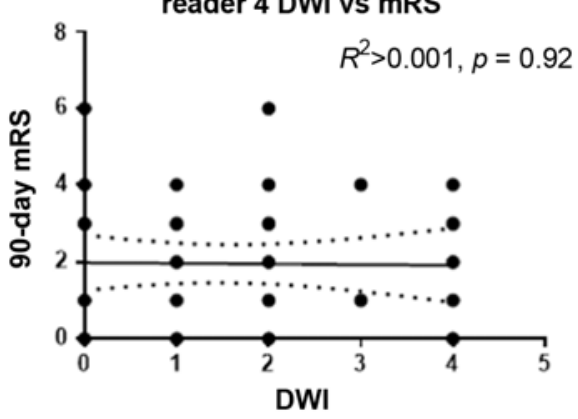

(F)

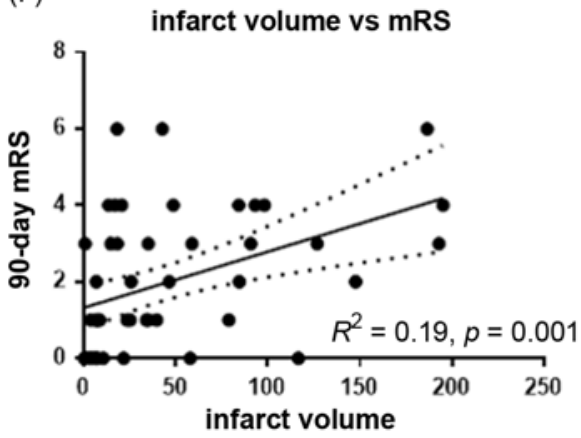

Figure 4. Post-MT case (A) DWI and (B) ADC maps in which the mRS was rated to be low (mRS 0-1) by readers on the basis of DWI findings and was ultimately mRS 4 at 90 days.

display this pattern on CTP, a wisdom that is now commonly accepted. $^{26}$ A penumbral pattern is defined as an infarct core $<70 \mathrm{~mL}$, penumbral volume $>15 \mathrm{~mL}$, and a total hypoperfused volume:core volume ratio of $>1.8$. It may be that DWI hyperintensity should similarly regarded as at-risk tissue which is not reflective of the final functional insult despite longer-term MR findings, with perfusion-weighted imaging possibly strengthening prognostication. ${ }^{27,28}$ Furthermore, while it has been shown that FLAIR lesions at day 2-3 in characteristic motor control regions (i.e. corona radiata, internal capsule, and insula) correlated with functional outcome, ${ }^{27}$ using this knowledge as a guide to predicting 90-day mRS on DWI was unhelpful. We conclude that DWI is at best useful for limited prognostication after deference to NIHSS score. It is not anecdotally uncommon to observe different outcomes than expected when using DWI as a predictor, and we thus urge caution in clinical practice. Instead, quantitative measures and clinical factors should be used preferentially.

\section{Limitations}

Limitations of our study include its retrospective nature during multiple endovascular epochs, which we sought to ameliorate through inclusion of all consecutive patients. Post-thrombectomy MRI was performed at a median of 2 days but a wider range, though readers were blinded to this information.

\section{Conclusion}

Our study suggests that that post-therapeutic DWI is an unreliable indicator for discharge and 90-day functional outcomes in the MT era for LVO patients. Overestimation of severity in patients with good outcome and underestimation of severity in patients with poor outcome were both common.

\section{ACKNOWLEDGMenTs}

The authors acknowledge the imaging technologists for their hard work in the care of stroke patients. 


\section{CONFLict OF InTERest}

No relevant conflicts of interest.

\section{Statement of Authorship}

Each author contributed equally and meaningfully to the preparation of this manuscript. This reflects both time and effort invested. AAD: study design, participant data acquisition, interpretation and analysis; primary manuscript preparation and editing, critical review and intellectual contribution; approval of the final version. AA, AEM, SD: expert analysis; independent statistical analysis; manuscript preparation and editing, critical review and intellectual contribution; approval of the final version. GW, AR: participant data acquisition; data analysis; manuscript preparation and editing, critical review and intellectual contribution; approval of the final version. $\mathrm{CH}$, AY, RIA: manuscript preparation and editing, critical review and intellectual contribution; approval of the final version. LDC, VXDY: expert neurointerventional care and analysis; expert neurosurgical interpretation and analysis; manuscript preparation and editing, critical review and intellectual contribution; approval of the final version.

\section{REFERENCES}

1. Hebert D, Lindsay MP, McIntyre A, et al. Canadian stroke best practice recommendations: stroke rehabilitation practice guidelines, update 2015. Int J Stroke. 2016;11(4):459-84.

2. Bonita R, Mendis S, Truelsen T, Bogousslavsky J, Toole J, Yatsu F. The global stroke initiative. Lancet Neurol. 2004;3(7):391-3.

3. Donkor ES. Stroke in the 21(st) century: a snapshot of the burden, epidemiology, and quality of life. Stroke Res Treat. 2018; 2018:3238165.

4. Sabzghabaei A, Aeinechian S, Shojaee M, Kashani P, Manouchehrifar M. Epidemiological features of ischemic brain stroke; a crosssectional hospital-based study. Arch Neurosci. 2019;6(2):e74362.

5. Gorelick PB. The global burden of stroke: persistent and disabling. Lancet Neurol. 2019;18(5):417-8.

6. Demaerschalk BM, Hwang HM, Leung G. US cost burden of ischemic stroke: a systematic literature review. Am J Manag Care. 2010;16(7):525-33.

7. Katan M, Luft A. Global burden of stroke. Semin Neurol. 2018;38(2):208-11.

8. Feigin VL, Nichols E, Alam T, et al. Global, regional, and national burden of neurological disorders, 1990-2016: a systematic analysis for the Global Burden of Disease Study 2016. Lancet Neurol. 2019;18(5):459-80.

9. Berkhemer OA, Fransen PSS, Beumer D, et al. A randomized trial of intraarterial treatment for acute ischemic stroke. N Engl J Med. 2014;372(1):11-20.

10. Campbell BC, Mitchell PJ, Kleinig TJ, et al. Endovascular therapy for ischemic stroke with perfusion-imaging selection. N Engl J Med. 2015;372(11):1009-18.

11. Saver JL, Goyal M, Bonafe A, et al. Stent-retriever thrombectomy after intravenous t-PA vs. t-PA alone in stroke. N Engl J Med. 2015;372(24):2285-95.
12. Goyal M, Demchuk AM, Menon BK, et al. Randomized assessment of rapid endovascular treatment of ischemic stroke. N Engl J Med. 2015;372(11):1019-30.

13. Kerr DM, Fulton RL, Lees KR. Seven-day NIHSS is a sensitive outcome measure for exploratory clinical trials in acute stroke: evidence from the virtual international stroke trials archive. Stroke. 2012;43(5):1401-3.

14. Broderick JP, $\mathrm{Lu} \mathrm{M}$, Kothari $\mathrm{R}$, et al. Finding the most powerful measures of the effectiveness of tissue plasminogen activator in the NINDS tPA stroke trial. Stroke. 2000;31(10): 2335-41.

15. Al-Ajlan FS, Goyal M, Demchuk AM, et al. Intra-arterial therapy and post-treatment infarct volumes: insights from the ESCAPE randomized controlled trial. Stroke. 2016;47(3):777-81.

16. Kwah LK, Diong J. National Institutes of Health Stroke Scale (NIHSS). J Physiother. 2014;60(1):61.

17. Baek JH, Kim K, Lee YB, et al. Predicting stroke outcome using clinical- versus imaging-based scoring system. J Stroke Cerebrovas Dis. 2015;24(3):642-8.

18. Raza SA, Rangaraju S. A review of pre-intervention prognostic scores for early prognostication and patient selection in endovascular management of large vessel occlusion stroke. Interventional Neurol. 2018;7(3-4):171-81.

19. Johnston KC, Barrett KM, Ding YH, Wagner DP. Clinical and imaging data at 5 days as a surrogate for 90-day outcome in ischemic stroke. Stroke. 2009;40(4):1332-3.

20. Johnston KC, Wagner DP, Wang XQ, et al. Validation of an acute ischemic stroke model: does diffusion-weighted imaging lesion volume offer a clinically significant improvement in prediction of outcome? Stroke. 2007;38(6):1820-5.

21. Turc G, Apoil M, Naggara O, et al. Magnetic resonance imagingDRAGON score: 3 -month outcome prediction after intravenous thrombolysis for anterior circulation stroke. Stroke. 2013; 44(5):1323-8.

22. Sajobi TT, Menon BK, Wang M, et al. Early trajectory of stroke severity predicts long-term functional outcomes in ischemic stroke subjects: results from the ESCAPE Trial (endovascular treatment for small core and anterior circulation proximal occlusion with emphasis on minimizing $\mathrm{CT}$ to recanalization times). Stroke. 2017;48(1):105-10.

23. Govan L, Langhorne P, Weir CJ. Categorizing stroke prognosis using different stroke scales. Stroke. 2009;40(10):3396-9.

24. Skagen K, Skjelland M, Russell D, Jacobsen EA. Large-vessel occlusion stroke: effect of recanalization on outcome depends on the national institutes of health stroke scale score. J Stroke Cerebrovasc Dis. 2015;24(7):1532-9.

25. Todo K, Sakai N, Kono T, et al. National institutes of health stroke scale-time score predicts outcome after endovascular therapy in acute ischemic stroke: a retrospective single-center study. J Stroke Cerebrovasc Dis. 2016;25(5):1187-91.

26. Wannamaker R, Guinand T, Menon BK, et al. Computed tomographic perfusion predicts poor outcomes in a randomized trial of endovascular therapy. Stroke. 2018;49(6):1426-33.

27. Cheng B, Forkert ND, Zavaglia M, et al. Influence of stroke infarct location on functional outcome measured by the modified Rankin scale. Stroke. 2014;45(6):1695-702.

28. Kakuda W, Lansberg MG, Thijs VN, et al. Optimal definition for PWI/DWI mismatch in acute ischemic stroke patients. J Cereb Blood Flow Metab. 2008;28(5):887-91. 